\title{
Study of Correlation between Milk Yield and Intestinal Microbes in Chinese Holstein Cows under the Same Diet
}

\author{
Xiuying W, Hongyu $\mathbf{W}^{*}$, Zhenya $Y$, Guozhen $\mathbf{W}$ and Xia X \\ School of Life Sciences, Jiangsu Normal University, Xuzhou, China
}

\begin{abstract}
The purpose of this study is to characterize and compare the gut microbes in six Chinese Holstein cows ( $\mathrm{CHC}$, $\mathrm{CHC} 2, \mathrm{CHC} 3, \mathrm{CHC} 4, \mathrm{CHC} 5, \mathrm{CHC} 6)$ under the same diet but different milk yields. High-throughput sequencing analysis was used to reveal and compare bacterial communities in faeces. The results showed 13 phyla in the six samples and the most dominant phylum was Firmicutes (approximately accounts for $71 \%$ OTUs), in which $18 \%$ OTUs were affiliated with Ruminococcaceae. Bacteroidetes was the subdominant phylum, which contributed to $17.5 \%$ of the total OTUs. While the majority of the bacterial genera found were unclassified, Solibacillus and Acinetbacter were the first and second predominant genera. Among the cases, the diversity and abundance of gut microbes in the Chinese Holstein cows have no significant difference under the same diet, which suggests that the relationship between milk yield and gut microbes is stable. The factors related to milk yield were calculated with spearman's rank $(p<0.05)$, the results showed that milk yield is significantly associated with age $(P=0.029)$ and body length $(P=0.021)$ of Chinese Holstein cows. By LEfSe analysis (LDA threshold of 2), screening out microorganisms with significant differences in the gut of different milking Chinese Holstein cows. For the reluts, Lachnospiraceae, Mollicutes, Tenericutes Mollicutes, Tenericutes apparently enriched in HMY, but only Fibrobacteraceae apparently enriched in LMY. This indicates microbes play an important role in the milk production of dairy Chinese Holstein cows.
\end{abstract}

Keywords: Intestinal microbial diversity; Chinese Holstein cows; Milk yield; High-throughput sequencing

\section{Introduction}

With the continuous improvement of living standard, people's consumption and demand for milk has obviously increased. Importantly, this phenomenon not only provides opportunities for the dairy industry, but also presents a significant challenge. In order to enhance the profitability of Chinese Holstein cows, it is necessary to understand the factors that affect its reproduction and the ability to produce milk. Some people have been studying the factors that affect milk production, which shows that the milk production is a result of the interaction between environmental and genetic factors. The environmental factors including milking methods, management practices, feeding system, season and geographical area and individual factors such as first-calving age, month of calving, parity and calving interval, calving ease, number of progeny born, significantly affect milk, butterfat and protein yields [1-3]. According to Kunaka and Hassan, the fourth parity and those calving in the winter season had the best milk yields $[4,5]$. Besides, the concentration and yield were influenced by feeding system, milking intervals and automatic milking systems [6-10]. Months of calving had a significant effect on milk, fat and protein yield, but had no effect on the percentages of fat and protein. The highest yields were in the months of May to August. On genetic factors, the histidine ammonia-lyse gene (HAL) which was identified as affecting milk production traits by genome-wide association study in Chinese Holstein cows, encodes the histidine ammonia-lyase [11]. In addition, the evidence has been provided for QTL (quantitative trait loci) on BTA3 (affecting fat and protein percentages), BTA6 (affecting fat and protein percentages), BTA14 (affecting fat percentages), and BTA20 (affecting protein percentages) [12]. Although the factors affecting milk production have been studied in many aspects, there has been no study to explore the influence of intestinal microorganisms on milk production in Chinese Holstein cows.

More importantly, the ruminant gastrointestinal tract is rich in microbes, most of which are anaerobic bacteria that play an important role in the digestion of fodder. To provide energy for the host, the 70$75 \%$ of the degradation and fermentation of daily fodder compounds were charged with archaea, ciliate protozoa and anaerobic fungi [13]. The host ingests the larger molecular weight lignin, cellulose and hemicellulose that cannot be directly utilized, but can be hydrolyzed and converted to short-chain fatty acids by microbes. What's more, these microbes can eliminate the toxins produced by the host metabolic processes [14]. With further research, more and more people have recognized the key role of the gut microbes in the host's absorption and metabolism of nutrients. There is no doubt that once the gastrointestinal tract microbial structure changed, the host's energy metabolism would be out of balance.

Microorganisms are ubiquitous, but so far many studies have shown that most bacteria in environmental samples cannot be isolated via the recognized methods. With the development of DNA sequencing technology, researchers have focused on the cultureindependent metagenomic approaches, using either a sequence-based or a functional-based application [15]. Over the past two decades, the field of environmental ecology has made tremendous progress, and a wide variety of methods using signature lipid biomarkers and nucleic acids have been developed to describe and characterize the functional and phylogenetic diversity of microorganisms [16]. The advent of

*Corresponding author: Hongyu W, School of Life Science, Jiangsu Normal University, Shanghai Road, Tongshan New District, Jiangsu, China, Tel: +86 13815310346; E-mail: wenhy@jsnu.edu.cn

Received July 15, 2018; Accepted September 27, 2018; Published September 29, 2018

Citation: Xiuying W, Hongyu W, Zhenya Y, Guozhen W, Xia X (2018) Study of Correlation between Milk Yield and Intestinal Microbes in Chinese Holstein Cows under the Same Diet. J Microb Biochem Technol 10: 112-118. doi: 10.4172/19485948.1000403

Copyright: ( $) 2018$ Xiuying W, et al. This is an open-access article distributed under the terms of the Creative Commons Attribution License, which permits unrestricted use, distribution, and reproduction in any medium, provided the original author and source are credited. 
such approaches has allowed microbial communities to be studied with greater precision in comparison with traditional techniques. The polymerase chain reaction (PCR) analysis provides a sensitive and specific means for detecting and monitoring microorganisms living in complex environmental matrices $[17,18]$. The Polymerase Chain Reaction-Denaturing Gradient Gel Electrophoresis (PCR-DGGE), as a conventional molecular technique, is a powerful molecular method for rapid detection of microbial community changes or comparative analysis of environmental samples, offering more accurate information about distribution and composition of microbial species [19]. The development of the above technologies laid the foundation for sequencing technology. Metagenome which means the genomes of the total microbiota found in nature has been studied in a deep-going way by sequencing methods. Traditional sequencing of nucleic acid molecules based on Sanger sequencing technology is the first generation DNA sequencing technology, which is very time-consuming and laborintensive. The deficiencies of traditional techniques are effectively offset since high-throughput sequencing techniques have been introduced [20]. The most fundamental step in molecular biology for microbial strains, and even more, for microbial community structure analysis is DNA extraction [21]. High-throughput sequencing technologies have a major impact on the life sciences by allowing the rapid accurate sequencing of very large numbers of about $200 \mathrm{bp}$ nucleotide sequences, in applications ranging from genome sequencing and resequencing to digital microarrays and ChIP-Seq experiments [22]. With the expansion of serial numbers, high-throughput sequencing technologies have brought new bioinformatics challenges to the storage and sharing of sequencing data. Compared with traditional sequencing methods, large-scale parallel sequencing technology can obtain sequence information in a short period of time $[23,24]$. The development of second generation sequencing methods has enabled large scale DNA variation studies at moderate cost [25]. The way has been used to explore microbes in the gut of mice, waste water treatment plants, and the rumen microbes of Sika deer $[15,26,27]$. Several studies have also applied pyrosequencing to reveal the microbiota in food such as yond bap and Italian salami $[28,29]$. It is also widely used in modern medicine such as research on diseases caused by genetic mutations.

To develop an in-depth and comprehensive understanding of the bacterial diversity and abundance in feces of Chinese Holstein cows under the same diet, high-throughput sequencing techniques were adopted to reveal the $16 \mathrm{~S}$ rRNA genes. According to the results, it could learn that all of the species in feces of Chinese Holstein cows will contribute to further studying these species, which could provide a reliable theoretical foundation for future functional research, suggesting its relevance to production performance and disease.

\section{Materials and Methods}

\section{Experimental animals}

Xuzhou is located in Jiangsu Province, China. In this study, the fresh fecal samples of cows were collected from cattle farming, which is a specialized farming cooperative. A total of 171 Chinese Holstein cows were domesticated in the farm. Their breeding relies on the green ecological feeds, such as Leymus chinensis, alfalfa from America, cottonseed, silage, soyabean and other agricultural product materials. The proportion of dietary ingredients has been adjusted to suit the needs of dairy cows of different ages or at different lactation periods. All Chinese Holstein cows related to this study were approved by the Institutional Animal Care.

\section{Sample collection}

The fresh feces were obtained from these Holstein cows rectums which were fed the same fodder. All samples were put immediately into sterile test-tubes by professional dairy breeder. On arrival at the laboratory, the feces were chilled to $4^{\circ} \mathrm{C}$ to reduce die-off of bacteria and to allow it to be used for up to 6 days. Otherwise the samples in sterile test-tubes were frozen with steps in liquid nitrogen and stored at $-80^{\circ} \mathrm{C}$ until extraction of DNA.

\section{DNA extraction}

Excluding non-lactating period, use of antibiotics which was used form birth, underage cows, etc., finally selected 6 cows as experimental subjects. The fecal samples of the six cows were used for DNA extraction using the Stool DNA Extraction Kit (Omega, USA) following the manufacturer's instructions. For each sample, DNA was extracted in triplicate to avoid bias and the extracts from the same sample were pooled, purity of DNA extracted was verified by electrophoresis on ethidium bromide staining $1 \%$ agarose gels and concentration was analyzed spectrophotometrically using the M200pro (TECAN, Switzerland). The extracted DNA was stored at $-80^{\circ} \mathrm{C}$ until used. The V4-V5 region of the bacteria $16 \mathrm{~S}$ rRNA gene were amplified by PCR $\left(95^{\circ} \mathrm{C}\right.$ for $2 \mathrm{~min}$, followed by 25 cycles at $95^{\circ} \mathrm{C}$ for $30 \mathrm{~s}, 55^{\circ} \mathrm{C}$ for $30 \mathrm{~s}$, and $72^{\circ} \mathrm{C}$ for $30 \mathrm{~s}$ and a final extension at $72^{\circ} \mathrm{C}$ for $5 \mathrm{~min}$ ). The primers used were 515F 5'-barcode-GTGCCAGCMGCCGCGG-3' and 907R 5'-barcode- CCGTCAATTCMTTTRAGTTT-3'. PCR reactions were performed in triplicate $20 \mu \mathrm{L}$ mixture containing $4 \mu \mathrm{L}$ of $5 \times$ FastPfu Buffer, $2 \mu \mathrm{L}$ of $2.5 \mathrm{mM}$ dNTPs, $0.8 \mu \mathrm{L}$ of each primer $(5 \mu \mathrm{M}), 0.4 \mu \mathrm{L}$ of FastPfu Polymerase, and 10 ng of template DNA.

\section{llumina MiSeq sequencing}

Deep sequencing was performed on Illumina sequencing with MiSeq using paired-end technology provided by Shanghai Majorbio Co. Ltd, China. Prior to sequencing, PCR amplicons were extracted from 2\% agarose gels and purified using the AxyPrep DNA Gel Extraction Kit (Axygen Biosciences, Union City, CA, USA) according to the manufacturer's instructions and quality controlled on a QuantiFluor $^{\text {Tx }}$-ST blue fluorescence quantitative system (Promega, USA). Following quantitation, purified amplicons from each reaction mixture were pooled in equimolar and paired-end sequenced $(2 \times 250)$ on an Illumina MiSeq platform according to the standard protocols.

\section{Bioinformatics data analysis}

Operation taxonomic units are usually defined by $16 \mathrm{~S}$ rRNA gene gene similarities. The similarity percent chosen is often $97 \%$ for short reads. It is used in place of taxonomic organization such as phylum and genus. Simultaneously, the development of specialized software tools such as Mothur, the RDP classifier, and QIIME allowed the analysis of large datasets.

In order to get every OTU corresponding species classification information, RDP classifier bayesian algorithm was adopted to analyze the sequences on behalf of OTU in the set $97 \%$ of OTU sequence similarity and the composition of each sample at every level (domain, kingdom, phylum, class, order, family, genus, species) was also recorded. The following are $16 \mathrm{~S}$ rRNA gene database of Bacterial (using silva databases without special version).

Silva (Release115 http://www.arb-silva.de); RDP (Release 11.1 http://rdp.cme.msu.edu/); Greengene (Release 13.5 http://greengenes. secondgenome.com/ ); Mothur (version v.1.30.1 http://www.mothur. org/wiki/Schloss SOP\#Alpha diversity) 


\section{Results}

Whole fecal microbes samples were collected from six healthy Holstein cows, detailed information about the six samples was recorded, the milk yield is daily (Table 1). The six Holstein cows were penned and fed with $1 \mathrm{~kg}$ Leymus chinensis, $3.5 \mathrm{~kg}$ alfalfa, $2 \mathrm{~kg}$ cottonseed, $22 \mathrm{~kg}$ silage, $0.75 \mathrm{~kg}$ soybean and $12 \mathrm{~kg}$ other agricultural product materials every day for 2 months.

In this study, based on homologous sequence alignment method and clustering with information extracted from RDF and BLAST databases, the unique representative sequence reads were obtained, which were delimited for further analysis (as the Table 2 showed 21,230, 11,424, $30,526,25,666,16,686$, and 14,032 effective reads of the $\mathrm{CHC} 1, \mathrm{CHC} 2$, $\mathrm{CHC} 3, \mathrm{CHC} 4, \mathrm{CHC} 5$ and $\mathrm{CHC} 6)$. Using the software program Mothur and sequence identity criteria cut off of $97 \%$, these sequences were assigned to some Operational taxonomic units (OTUs). Chaol index estimates greater species richness than it would for a sample without rare OTUs. Besides the Chaol estimator, Mothur includes several other species richness estimators and a wrapped version of catchall, which includes Ace estimator. The bacterial phylotype richness levels can also be reflected by using Shannon index and Simpson diversity index (Table 2), which also explored that the $\mathrm{CHC} 4$ had the highest bacterial diversity in the six samples. The coverage reflected sequencing depth and the result shows that the bacterial phylotype from the samples were sequenced more than $99 \%$, but this sequencing depth was not enough to cover the whole bacterial diversity community. Therefore, it is worthwhile to establish a more efficient sequencing platform to detect more bacterial species in the cattle feces.

Six cows are divided to two groups, cows with high milk yield (CHC1-3) and low-milk yield-cows (CHC4-6), according to milk yield. The milk yield between HMY and LMY showed significant differences by One Way ANOVA One-way analysis $(\mathrm{P}=0.016)$ (Figure $1 \mathrm{~A})$. The Shannon diversity curves of all samples reached the saturation phase, suggesting that although additional new phylotype would possibly identified by increasing the sequencing depth, and the majority of bacterial phylotype for the samples had already been captured in the current analysis. As Shannon Wiener curve reflects the samples of microbial diversity index, the curve tends to be flat showing that the sequencing data is enough to reflect the whole bacteria phylotype in samples truly, which can also be concluded that a little distinction of

\begin{tabular}{|c|c|c|c|c|c|c|}
\hline Identifier & CHC1 & CHC2 & CHC3 & CHC4 & CHC5 & CHC6 \\
\hline Weight/kg & 600 & 580 & 580 & 550 & 609 & 650 \\
\hline Body length/m & 1.70 & 1.68 & 1.70 & 1.73 & 1.72 & 1.73 \\
\hline Age/year & 5 & 5.2 & 4.8 & 5.5 & 5.6 & 6 \\
\hline Parity & 2 & 1 & 3 & 2 & 2 & 4 \\
\hline Milk yield/kg & 10 & 12 & 20 & 30 & 30 & 42 \\
\hline
\end{tabular}

Table 1: Body condition of six healthy Holstein cows.

\begin{tabular}{|c|c|c|c|c|c|}
\hline \multirow{2}{*}{ Sample ID } & \multirow{2}{*}{ Reads } & \multicolumn{5}{|c|}{$\mathbf{0 . 9 7}$} \\
\cline { 3 - 6 } & & OTU & Shannon & Simpson & Coverage \\
\hline CHC1 & 21230 & 619 & 4.52 & 0.0493 & 0.995949 \\
\hline CHC2 & 11424 & 510 & 4.47 & 0.0483 & 0.990371 \\
\hline CHC3 & 30526 & 613 & 4.46 & 0.0460 & 0.997644 \\
\hline CHC4 & 25666 & 655 & 4.70 & 0.0451 & 0.997740 \\
\hline CHC5 & 16686 & 626 & 4.56 & 0.0618 & 0.994127 \\
\hline CHC6 & 14032 & 580 & 4.32 & 0.0696 & 0.990094 \\
\hline
\end{tabular}

species diversity of the bacterial community existed from this samples. Figure $1 \mathrm{~B}$ showed that the sequencing data is enough to reflect the whole bacteria phylotype in sample truly, and it can also be concluded that a little distinction of species richness and diversity of the bacterial community existed from this samples. The boxplot shows no significant difference in OTU number (Figure 1C), Shannon index (Figure 1D), Simpson index (Figure 1E) between high-yielding dairy cows and lowyielding dairy cows $(\mathrm{P}>0.05)$.

The boxplot contains five horizontal line, from top to bottom, respectively, for the upper edge, the upper quartile, the median, the lower quartile, the lower edge.

All sequences were classified from phylum to genus using the program Mothur with the default setting, currently 13 different phyla and 100 genera were identified from these samples (Figure $2 \mathrm{~A}$ and 2B). The Figure 2 illustrated that the samples included the maximum number of phyla [30]. The six samples showed relatively similarity diversity, where Firmicutes (72\% OTUs of CHC1, 68\% OTUs of CHC2, $73 \%$ OTUs of $\mathrm{CHC} 3,72 \%$ OTUs of $\mathrm{CHC} 4,71 \%$ OTUs of CHC5, 70\% OTUs of CHC6), was the highest proportion groups, Bacteroidetes (17\% OTUs of CHC1, 20\% OTUs of CHC2, 17\% OTUs of $\mathrm{CHC} 3,16 \%$ OTUs of CHC4, $16 \%$ OTUs of $\mathrm{CHC} 5,19 \%$ OTUs of CHC6) and Proteobacteria (1.2\% OTUs of CHC1, 1.4\% OTUs of CHC2, $1.3 \%$ OTUs of $\mathrm{CHC} 3,1.5 \%$ OTUs of CHC4, $1.4 \%$ OTUs of CHC5,1.2\% OTUs of CHC6) were the second and third predominant bacteria at phylum level, Tenericutes and Spirochaetae occupied a small proportion (Figure 2A). The uncultured bacteria at the genus level represented the majority of the OTUs like Ruminococcaceae (CHC1 $21 \%$, CHC2 22\%, CHC3 23\%, CHC4 25\%, CHC5 20\%, CHC6 19\%), which is the dominant genus. In addition, the Solibacillus (CHC1 19\%, CHC2 19\%, CHC3 13\%, CHC4 19\%, CHC5 24\%, CHC6 25\%) was the less proportion groups. RC9-gut-group ( $\mathrm{CHC1} 6 \%$, $\mathrm{CHC} 29 \%$, $\mathrm{CHC} 3$ $7 \%$, $\mathrm{CHC} 46 \%$, CHC5 7\%, CHC6 9\%) accounted for a third of the total (Figure 2B). The results show that the six samples under the same diet have the similar bacterial community.

In order to confirm the correlation between gut microbe and milk yield on cows, LEfSe analysis (linear regression analysis) was used to obtain the microbial groups with significant effects in the two sets of data. The results showed that the species of low milk yield cows were single and the Fibrobacter accountfor the main position. The highyield milk group is rich in species diversity, including Lachnospiraceae, Mollicutes and Teneriquets (Figure 3).

In addition, the correlations of milk yield and body index were calculated with Spearman's rank $(\mathrm{p}<0.05)$ (using software: IBM SPSS Statistics 19). The results showed that milk yield is significantly associated with age $(\mathrm{P}=0.029)$ and body length $(\mathrm{P}=0.021)$ of dairy cows (Table 3 ) but the correlation between milk yield and community diversity estimator is not obvious (Table 4).

\section{Discussion}

Around 2008, Sanger sequencing was still the most common approach, as contemporary next-generation sequencing with read lengths of 100 base-paris or less were unable to significantly differentiate taxa. Bioinformatics and software platform development is able to provide a thorough characterizing of microbiota community diversity in environmental samples (soil, water, sludge, manure), which also helps to gain their potential function genes by splicing and ORF prediction of sequenced reads. In the study, the bacterial communities in the feces of Chinese Holstein cows were studied. Firmicutes and 


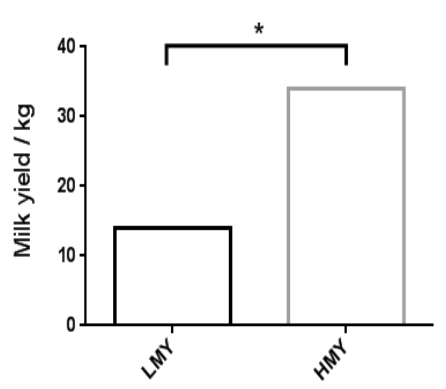

A. The milk yield of LMY and HMY $(*$ means $\mathrm{P} \leq 0.05)$.

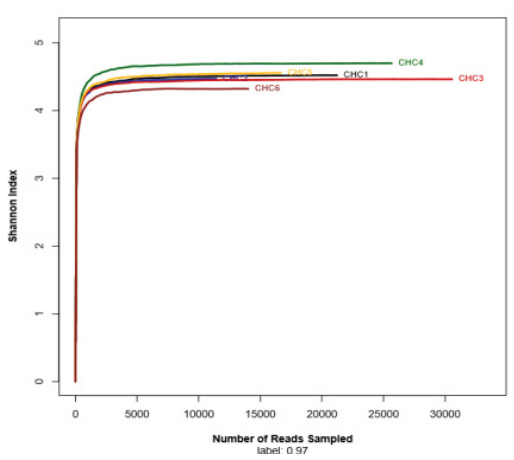

B. Shannon Wiener curves of six samples.

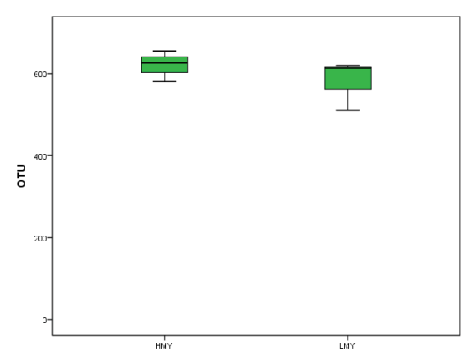

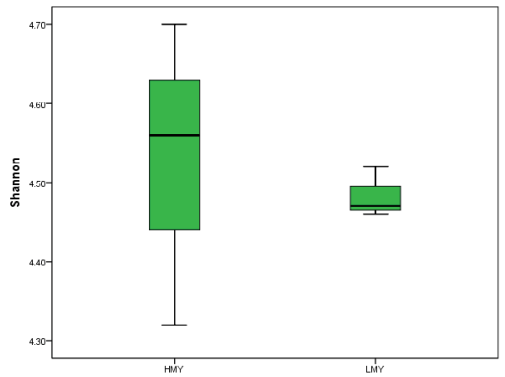

D. Shannon Index

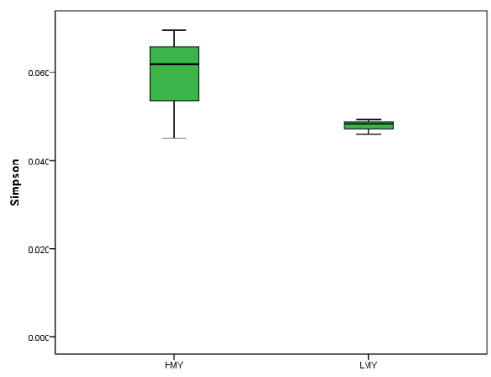

E. Simpson Index

C. Comparison between low milk yield and high milk yield of OTU number.

Figure 1: Analysis of community diversity of low milk yield (LMY) and high milk yield (HMY).

Bacteroidetes were the first and the second predominant bacteria at phylum level, which was in line with results from some previous studies [31-33]. With the development of science and technology, anaerobic digestion is an alternative method for the treatment of animal manure and wastewater [34]. Overall, Firmicutes and Bacteroidetes were the most highly represented phyla in the anaerobic digesters [35]. One study observed that stable performance of anaerobic digestion process was positively correlated with the abundance of Firmicutes populations but not those of Bacteroidetes populations, but the $\mathrm{F} / \mathrm{B}$ ratio as a useful process stability indicator in industrial application [19]. Further, the bacterial diversity and abundance in distinction of the fence of cows were revealed by analyzing $16 \mathrm{~S}$ rRNA gene sequences in a cultureindependent manner. From the results we obtained that the 106 samples harbored the highest diversity of bacteria. At a distance cutoff $3 \%, 655$ OTUs were obtained from 25,666 sequences, indicating that the 106 sample is a highly species-rich ecosystem, at the same time,
130 samples harbored the least diversity of bacteria. For the Firmicutes/ Bacteroidetes ratio, significant differences between infants, adults and the elderly $(0.4,10.9$ and 0.6 , respectively) were observed. Notably, no significant differences were found between the infants and elderly [36]. While the recent studies of $16 \mathrm{~S}$ rRNA genes in the mammalian gut microbiota distinguished a higher Firmicutes/Bacteroidetes ratio in obese individuals compared to lean individuals [31].

The phyla that are less abundant, in particular, Cyanobacteria, Elusimicrobia, Fibrobacteres, Lentisphaerae, Planctomycetes, Proteobacteria, Spirochaetae, Tenericutes and Verrucomicrobia, are normally found in a wide variety of environments and play various roles in the anaerobic digestion of animal manure. These phyla showed that the percentage of total values differentiated between the samples, indicating that there are more complex microbial components in different individuals. 


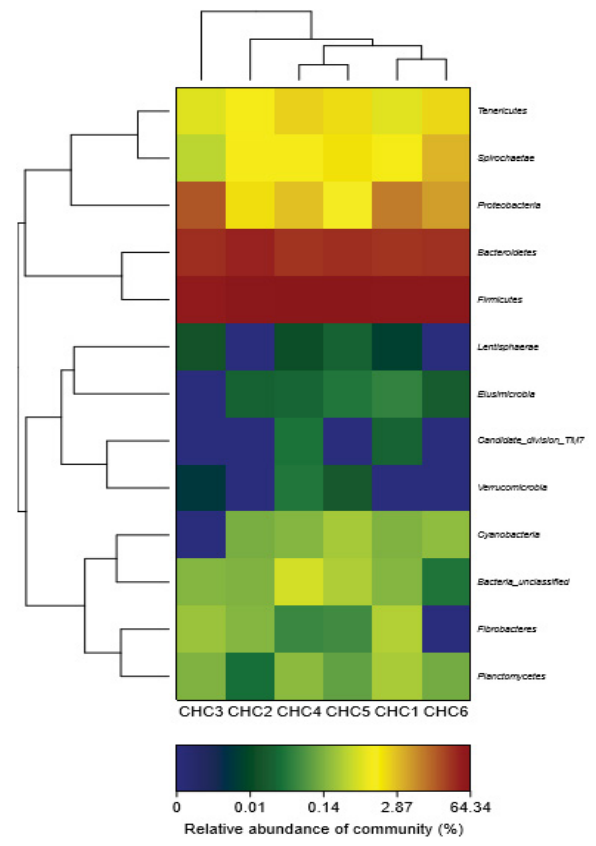

A
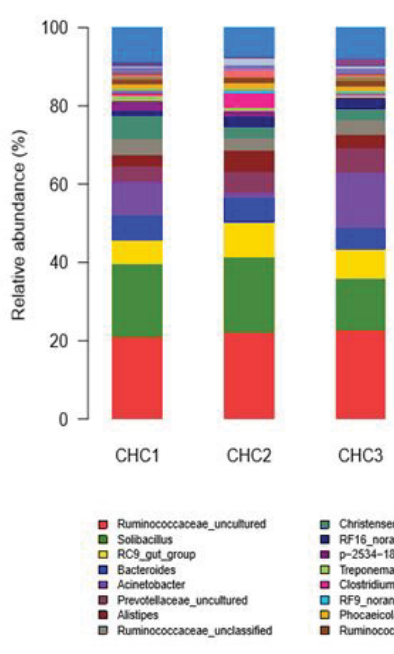

$\mathrm{CHC3}$

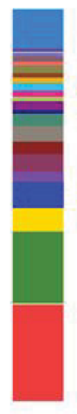

$\mathrm{CHC} 4$

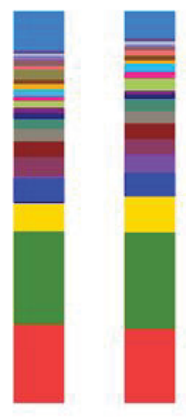

$\mathrm{CHC5} \quad \mathrm{CHC6}$

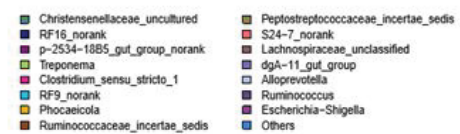

B

A. The heat map plot depicts the relative percentage of each bacterial phylum. Each row represents a species, each column represents a sample, the color represents the relative abundance of the species in the sample, the darker the color (red), indicating that the higher the abundance of the species, while the more blue the lower.

B. Bacterial community structure at genus level. Each row represents phylum or genus, and each column represents an individual cow.

Figure 2: The community composition of six samples.

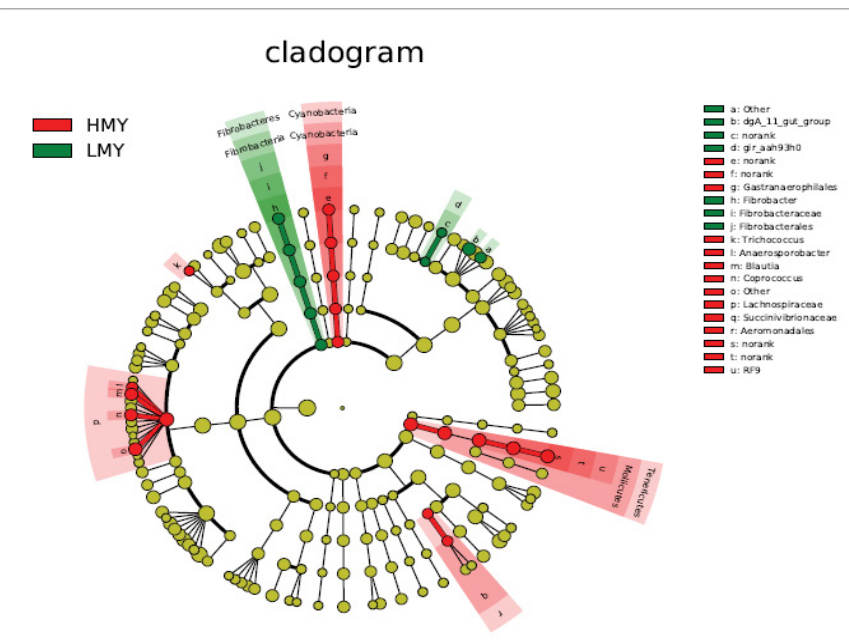

Figure 3: Taxonomic representation of statistical differences in relative abundances between group with high and low milk yield.

Differences are represented in the colour of the most abundant class (red: cows with high milk yeild, green: another group of cows under low milk yeild, yellow: non-significant). Each circle's diameter is proportional to the taxon's abundance.

Within the phylum Firmicutes, Clostridia were the largest class in the bacterial community, followed by Bacilli, Selenomonadales, Erysipelotrichaceae. This agrees with the results from other authors, who suggested that many Clostridia are involved in the breakdown of polysaccharides and therefore they play an important role in the hydrolysis step of plant biomass [30]. Solibacillus and Acinetobacter were the dominant genera for samples from Chinese Holstein cows. Except the uncultured bacterial, Solibacillus was the predominant genus in these samples which holds the largest proportion in Firmicutes. The Solibacillus bacteria present in the feces may possibly play an important function, such as excretion of positive biocontrol agents that have quorum-quenching activities and keep pathogens away [37]. Interestingly, a species of Soilbacillus, Solibacillus silvestris, has the ability to degrade $\mathrm{N}$-acylhomoserine lactones [38]. About the role of foods in the chain of transmission of Acinetobacters and the emergence of different Acinetobacter spp. in foods is known a little. Currently, there is no recognized standard procedure to isolate Acinetobacters from food in order to gain insight into the epidemiology ecology and food-related of Acinetobacters [39]. Acinetobacter was the largest genus of Proteobacteria which contained the largest class Gammaproteobacteria, a total of 7 known genera were identified from the proteobacterial sequences. Acinetobacter spp. is point out as they frequently take along various antibiotic resistance factors [40].

In recent years, the research of ruminants has been a hot issue. Cow dung is one of the most abundant and unexploited resource for cellulolytic enzyme production. It contains $35.4 \%$ cellulose, $32.6 \%$ hemicelluloses, $13.3 \%$ ash, and $1.4 \%$ nitrogen and many essential nutrients, such as $\mathrm{Ca}, \mathrm{Mg}, \mathrm{S}, \mathrm{Zn}, \mathrm{B}, \mathrm{Cu}$ and $\mathrm{Mn}$. The carbon and nitrogen ratio in cow dung manure is an indication that it could be a promising feedstock for culturing the microbes. The bioprocessing of these low cost feedstocks can help reduce the production cost of raw materials as well as environmental pollution [37]. 
Citation: Xiuying W, Hongyu W, Zhenya Y, Guozhen W, Xia X (2018) Study of Correlation between Milk Yield and Intestinal Microbes in Chinese Holstein Cows under the Same Diet. J Microb Biochem Technol 10: 112-118. doi: 10.4172/1948-5948.1000403

\begin{tabular}{|c|c|c|c|c|c|}
\hline \multicolumn{2}{|c|}{$\mathrm{N}=6$} & \multirow{2}{*}{$\begin{array}{c}\text { Milk yield/kg } \\
1\end{array}$} & \multirow{2}{*}{$\begin{array}{c}\text { Weight/kg } \\
0.470\end{array}$} & \multirow{2}{*}{$\begin{array}{c}\text { Body length } / \mathrm{m} \\
0.881^{*}\end{array}$} & \multirow{2}{*}{$\begin{array}{c}\text { Age/year } \\
0.858^{*}\end{array}$} \\
\hline \multirow{3}{*}{ Milk yield/kg } & Pearson correlation & & & & \\
\hline & Significant (bilateral) & & 0.347 & 0.021 & 0.029 \\
\hline & $\mathrm{N}$ & 6 & 6 & 6 & 6 \\
\hline \multirow{3}{*}{ Weight/kg } & Pearson correlation & 0.470 & 1 & 0.263 & 0.558 \\
\hline & Significant (bilateral) & 0.347 & & 0.614 & 0.250 \\
\hline & $\mathrm{N}$ & 6 & 6 & 6 & 6 \\
\hline \multirow{3}{*}{ Body length/m } & Pearson correlation & $0.881^{*}$ & 0.263 & 1 & 0.732 \\
\hline & Significant (bilateral) & 0.021 & 0.614 & & 0.098 \\
\hline & $\mathrm{N}$ & 6 & 6 & 6 & 6 \\
\hline \multirow{3}{*}{ Age/year } & Pearson correlation & $0.858^{*}$ & 0.558 & 0.732 & 1 \\
\hline & Significant (bilateral) & 0.029 & 0.250 & 0.098 & \\
\hline & $\mathrm{N}$ & 6 & 6 & 6 & 6 \\
\hline
\end{tabular}

*Significant correlation at 0.05 level (bilateral)

Table 3: The correlation between milk yield and body index.

\begin{tabular}{|c|c|c|c|c|c|}
\hline & & Milk yield $/ \mathbf{k g}$ & OTU & Shannon & Simpson \\
\hline \multirow{3}{*}{ Milk yield/kg } & Pearson correlation & 1 & 0.287 & -0.187 & 0.719 \\
\hline & Significant (bilateral) & & 0.581 & 0.723 & 0.108 \\
\hline & $\mathrm{N}$ & 6 & 6 & 6 & 6 \\
\hline \multirow{3}{*}{ OTU } & Pearson correlation & 0.287 & 1 & 0.591 & -0.110 \\
\hline & Significant (bilateral) & 0.581 & & 0.217 & 0.836 \\
\hline & $\mathrm{N}$ & 6 & 6 & 6 & 6 \\
\hline \multirow{3}{*}{ Shannon } & Pearson correlation & -0.187 & 0.591 & 1 & -0.591 \\
\hline & Significant (bilateral) & 0.723 & 0.217 & & 0.217 \\
\hline & $\mathrm{N}$ & 6 & 6 & 6 & 6 \\
\hline \multirow{3}{*}{ Simpson } & Pearson correlation & 0.719 & -0.110 & -0.591 & 1 \\
\hline & Significant (bilateral) & 0.108 & 0.836 & 0.217 & \\
\hline & $\mathrm{N}$ & 6 & 6 & 6 & 6 \\
\hline
\end{tabular}

*Significant correlation at 0.05 level (bilateral)

Table 4: The correlation between milk yield and community diversity estimator.

In this study the samples are not particularly sufficient, so the research of more sample size is needed to reveal the correlation between milk yield and intestinal microbes in the future. In addition, the milk composition should be considered, in terms of protein and fat, so that the mechanism of intestinal microbial action would be explored more accurately and deeply.

\section{Conclusion}

Studies on intestinal microbial composition among human beings indicated that each individual has his/her own unique predominant bacteria. All six samples studied contained the same most dominant bacterial populations. The results described above indicated that the diversity and richness of intestinal microbes of LMY are lower than HMY under the same diet. Firmicutes is the predominant bacteria in all six samples. High-throughput sequencing technologies used in this study are more comprehensive and systematic to measure the bacteria in the feces of Chinese Holstein cows. The results suggest that the different individuals of Chinese Holstein cows are similar at feces bacteria structure. They share some species which occupy larger proportion like Clostridia, Bacteroidia and Bacilli but there are still some species which not all samples are contained. The milk yield was related to the age and body length of Chinese Holstein cows, and the correlation between milk production and intestinal microbes was also significant. This paper reveals that intestinal microbes of Chinese Holstein cows have an important effect on milk production.

\section{Acknowledgement}

This work was support by Scientific and Technological Innovation Projects (KC17082) Promoted by Xuzhou in 2017 and Priority Academic Program Development (PAPD) of Jiangsu Higher Education Institutions. The authors wish to thank farm technicians who helped to collect fecal samples referred to this research. Finally the authors acknowledge Majorbio Biotech Co., Ltd., (Shanghai, China) for their help in sample sequencing.

\section{References}

1. Bernard NG, Edward HT, Bruce T (2014) Comparative evaluation of nongenetic factors affecting milk yield and composition of Red Dane and Jersey cattle in Zimbabwe. Springer Plus 3: 88.

2. Selvaggi M, D'Alessandro AG, Dario C (2017) Environmental and genetic factors affecting milk yield and quality in three Italian sheep breeds. J Dairy Res 84: 27-31.

3. Stocco G, Cipolat-Gotet C, Bobbo T, Cecchinato A, Bittante G (2017) Breed of cow and herd productivity affect milk composition and modeling of coagulation, curd firming and syneresis. J Dairy Sci 100: 129-145.

4. Kunaka K, Makuza SM (2005) Environmental Factors Affecting Milk Production in the Holstein-Friesian Population of Zimbabwe. Pak J Bio Sci 8: 989-994.

5. Hassan FA, Ali MA, Eltarabany MS (2017) Economic impacts of calving season and parity on reproduction and production traits of buffaloes in the sub-tropics. Environ Sci Pollut Res 24: 10528-10266.

6. Gulati A, Galvin N, Lewis E, Hennessy D, O'Donovan M, et al. (2017) Outdoo grazing of dairy cows on pasture versus indoor feeding on total mixed ration: Effects on gross composition and mineral content milk during lactation. J Dairy Sci 100: 1-14.

7. Kholif AE, Gouda GA, Olafadehan OA, Abdo MM (2017) Effects of replacement of Moringa oleifera for berseem clover in the diets of Nubian goats on feed utilisation, and milk yield, composition and fatty acid profile. Animal 12: 964-972. 
Citation: Xiuying W, Hongyu W, Zhenya Y, Guozhen W, Xia X (2018) Study of Correlation between Milk Yield and Intestinal Microbes in Chinese Holstein Cows under the Same Diet. J Microb Biochem Technol 10: 112-118. doi: 10.4172/1948-5948.1000403

8. Caroprese M, Albenzio M, Marino R, Muscio A, Zezza T, et al. (2007) Behavior, Milk Yield, and Milk Composition of Machine-and Hand-Milked Murgese Mares. J Dairy Sci 90: 2773-2777.

9. Lyons NA, Kerrisk KL, Garcia SC (2013) Comparison of 2 systems of pasture allocation on milking intervals and total daily milk yield of dairy cows in a pasture-based automatic milking system. J Dairy Sci 96: 4494-4504.

10. Speroni M, Pirlo G, Lolli S (2006) Effect of automatic milking systems on milk yield in a hot environment. J Dairy Sci 89: 4687-4693.

11. Wang HF, Jiang L, Wang WW, Zhang SL, Yin ZJ (2014) Associations between variants of the HAL gene and milk production traits in Chinese Holstein cows. BMC Genomics 15: 125.

12. Ashwell MS, Heyen DW, Sonstegard TS, Van Tassell CP, Da Y, et al. (2004) Detection of quantitative trait loci affecting milk production, health, and reproductive traits in Holstein cattle. J Dairy Sci 87: 468-475.

13. Eric P, Neil ME, Jean-Philippe M, Corinne B, Eric A (2013) The Effects of a Probiotic Yeast on the Bacterial Diversity and Population Structure in the Rumen of Cattle. Plos One 7: e67824.

14. Xu H, Huang W, Hou Q, Kwok L, Sun Z, et al. (2017) The effects of probiotics administration on the milk production, milk components and fecal bacteria microbiota of dairy cows. Chinese Sci Bull 62: 767-774.

15. Kim YS, Kim J, Park SJ (2015) High-throughput 16S rRNA gene sequencing reveals alterations of mouse intestinal microbiota after radiotherapy. Anaerobe 33: 1-7.

16. Mrozik A, Nowak A, Piotrowska-Seget Z (2014) Microbial diversity in waters, sediments and microbial mats evaluated using fatty acid-based methods. Int $\mathrm{J}$ Environ Sci Te 11: 1487-1496.

17. Chen M, Wu B, Chen T, Liu Z, Deng Z, et al. (2016) The impact of different DNA extraction methods on the analysis of microbial diversity of oral saliva from healthy youths by polymerase chain reaction-denaturing gradient gel electrophoresis. J Dent Sci 11: 54-58.

18. Narváez-Zapata JA, Rodríguez-ávila N, Ortega-Morales BO (2005) Method for recovery of intact DNA for community analysis of marine intertidal microbial biofilms. Mol Biotechnol 30: 51-56.

19. Chen S, Cheng H, Wyckoff KN, He Q (2016) Linkages of Firmicutes and Bacteroidetes populations to methanogenic process performance. J Ind Microbiol Biotechnol 43: 771-781.

20. Kohda M, Kumamoto K, Eguchi H, Hirata T, Tada Y, et al. (2016) Rapid detection of germline mutations for hereditary gastrointestinal polyposis/ cancers using HaloPlex target enrichment and high-throughput sequencing technologies. Fam Cancer 15: 553-562.

21. Tanase AM, Mereuta I, Chiciudean I, lonescu R, Milea L (2015) Comparison of Total DNA Extraction Methods for Microbial Community Form Polluted Soil. Agriculture and Agricultural Science Procedia 6: 616-622.

22. Daily K, Rigor P, Christley S, Xie X, Baldi $P$ (2010) Data structures and compression algorithms for high-throughput sequencing technologies. BMC Bioinformatics 11: 514

23. Sharma R, Thines M (2015) FastQFS - A tool for evaluating and filtering pairedend sequencing data generated from high throughput sequencing. Mycological Progress 14: 60 .
24. Yang $M Q$, Athey $B D$, Arabnia $H R$, Sung $A H$, Liu Q (2009) High-throughput next-generation sequencing technologies foster new cutting-edge computing techniques in bioinformatics. BMC Genomics 10: 11.

25. Kerstens HHD, Crooijmans RPMA, Veenendaal A, Dibbits BW, Chin-A-Woeng TFC, et al. (2009) Large scale single nucleotide polymorphism discovery in unsequenced genomes using second generation high throughput sequencing technology: applied to turkey. BMC Genomics 10: 479.

26. Ma Q, Qu Y, Shen W, Zhang Z, Wang J, et al. (2015) Bacterial community compositions of coking wastewater treatment plants in steel industry revealed by Illumina high-throughput sequencing. Bioresour Technol 179: 436-443.

27. Li ZP, Liu HL, Li GY, Bao K, Wang KY, et al. (2013) Molecular diversity of rumen bacterial communities from tannin-rich and fiber-rich forage fed domestic Sika deer (Cervus nippon) in China. BMC Microbiol 13: 151.

28. Liu X, Liu C, Zhang H, Gong F, Luo Y, et al. (2015) The bacterial community structure of yond bap, a traditional fermented goat milk product, from distinct Chinese regions. Dairy Sci Technol 95: 369-380.

29. Połka J, Rebecchi A, Pisacane V, Morelli L, Puglisi E (2015) Bacterial diversity in typical Italian salami at different ripening stages as revealed by high-throughput sequencing of $16 \mathrm{~S}$ rRNA amplicons. Food Microbiology 46: 342-356.

30. Kamada N, Chen GY, Inohara N, Ez GN (2013) Control of pathogens and pathobionts by the gut microbiota. Nat Immunol 14: 685-690.

31. Armougom F, Raoult D (2008) Use of pyrosequencing and DNA barcodes to monitor variations in Firmicutes and Bacteroidetes communities in the gut microbiota of obese humans. BMC Genomics 9: 576

32. Kim M, Felix TL, Loerch SC, Yu Z (2014) Effect of Haylage and Monensin Supplementation on Ruminal Bacterial Communities of Feedlot Cattle. Curr Microbiol 69: 169-175.

33. Kim M, Wells JE (2016) A Meta-analysis of Bacterial Diversity in the Feces of Cattle. Curr Microbiol 72: 145-151.

34. Resende JA, Godon JJ, Bonnafous A, Arcuri PB, Silva VL (2016) Seasonal Variation on Microbial Community and Methane Production during Anaerobic Digestion of Cattle Manure in Brazil. Microb Ecol 71: 735-746.

35. St-Pierre B, Wright A (2014) Comparative metagenomic analysis of bacteria populations in three full-scale mesophilic anaerobic manure digesters. Appl Microbiol Biotechnol 98: 2709-2717.

36. Mariat D, Firmesse O, Levenez F, Es VG, Sokol H (2009) The Firmicutes/ Bacteroidetes ratio of the human microbiota changes with age. BMC microbiol 9: 123.

37. Mao S, Huo W, Zhu W (2013) Use of Pyrosequencing to Characterize the Microbiota in the lleum of Goats Fed with Increasing Proportion of Dietary Grain. Curr Microbiol 67: 341-350.

38. Morohoshi T, Tominaga Y, Someya N, Ikeda T (2012) 2Fp21 Complete genome sequence and characterization of the $\mathrm{N}$-acylhomoserine lactonedegrading gene of the potato leaf-associated Solibacillus silvestris. J Biosci Bioeng 113: 20-25

39. Carvalheira A, Ferreira V, Silva J, Teixeira P (2016) Enrichment of Acinetobacter spp. from food samples. Food Microbiology 55: 123-127.

40. Juma NA, Manning G, Forsythe SJ (2016) Desiccation survival of Acinetobacter spp. in infant formula. Food Control 68: 162-166. 